\title{
LA CONFIGURACIÓN DE LA POLÍTICA REPRESENTATIVA: UNA PERSPECTIVA TRANSVERSAL
}

\section{CONFIGURING REPRESENTATIVE POLITICS: A CROSS-SECTIONAL PERSPECTIVE}

\author{
Alejandro Monsiváis Carrillo ${ }^{l}$ \\ amonsi@colef.mx
}

Fecha de recpeción: 3 abril 2013 - Fecha de acpetación: 15 octubre 2013

\begin{abstract}
Resumen
Este trabajo parte de la premisa de que es necesario repensar la representación política para entender los desafíos de la política democrática. El propósito es mostrar que la representación política se compone de procesos de autorización y rendición de cuentas, en los que el debate y la deliberación públicos desempeñan un papel clave. En este sentido, las relaciones representativas pueden contribuir a promover las normas de inclusión y participación democráticas. Además, se espera que esta formulación contribuya a analizar la construcción de discursos y reivindicaciones representativas, y que tienda puentes entre el estudio de los mecanismos electorales y no-electorales de representación.

Palabras clave: representación política, democracia, teoría normativa, inclusión, rendición de cuentas, deliberación, gobernanza participativa.
\end{abstract}

\begin{abstract}
The premise of this paper is that rethinking the concept of political representation is a necessary endeavor to understand the challenges that democratic politics is facing. The purpose is to show that political representation is constituted by process of authorization and accountability where political debates and public deliberation perform an influential role. In that sense, representative relationships can contribute to the promotion of the democratic norms of inclusion and participation. It is expected that this approach will contribute to analyze the construction of representative claims and discourses, and help bridge the study of electoral and non-electoral mechanisms of representation.
\end{abstract}

Keywords: political representation, democracy, normative theory, inclusion, accountability, deliberation, participatory governance

1 Profesor-Investigador, Departamento de Estudios de Administración Pública, El Colegio de la Frontera Norte, México. 
Un renovado interés por el concepto de representación política se ha extendido en diversos ámbitos de la teoría política contemporánea (Alonso et. al. 2011; Shapiro et al., 2009; Urbinati, 2006). Además, las cuestiones relacionadas con la representación política han estado habitualmente asociadas al análisis de los aspectos electorales y legislativos de los regímenes democráticos (Przeworski et. al. 1999). Esto ha motivado a diversos especialistas comprometidos con una concepción participativa de la democracia a enfocarse en temas relacionados con la esfera pública, la sociedad civil y los modelos emergentes de gobernanza participativa (Avritzer, 2002; Fung y Wright, 2003; Olvera, Dagnino y Panfichi, 2006). Sin embargo, la necesidad de repensar la relación entre la representación política y la teoría normativa de la democracia ha ganado notoriedad (Plotke, 1997; Urbinati y Warren, 2008). Y esto ha tenido lugar, precisamente, en el marco de una revitalización impulsada por los enfoques deliberativos y participativos en la teoría de la democracia (Gurza e Isunza, 2010; Parkinson, 2003; Peruzzotti y Seele, 2009).

Este trabajo pretende aportar elementos para incorporar el concepto de representación política al análisis político y el desarrollo de la teoría de la democracia. Se argumentará que la representación no es un fenómeno que acontece solamente en las instituciones representativas, sino que es un fenómeno político que articula discursos, reglas y acciones públicas. Del mismo modo, para analizar las consecuencias democráticas de la representación, es necesario prestar atención a las instituciones electorales y legislativas de los regímenes políticos, al igual que a distintos tipos de procesos, intervenciones y reivindicaciones que se expresan en escenarios no-electorales.

Este planteamiento será formulado en un plano analítico-normativo, lo cual significa que las cuestiones que aborda son de índole fundamentalmente conceptual, tratando de identificar las normas políticas que están implicadas en el debate y buscando soluciones que optimicen la integración entre esas normas. Como ha señalado Rehfeld (2010), el análisis normativo y la clarificación conceptual son tareas propias de una teoría política que pretenda contribuir a entender y explicar los fenómenos políticos empíricos. Una segunda aclaración que hay que hacer se refiere a la escala del planteamiento que se desarrollará en este trabajo) : esta formulación se circunscribe a los procesos políticos que acontecen al interior de los regímenes políticos nacionales. Este argumento puede extenderse hacia la política transnacional, pero tal formulación requiere un tratamiento aparte.

Así, el artículo comienza identificando algunos de los problemas que ponen en cuestionamiento la representación política en los regímenes democráticos contemporáneos. La segunda sección del trabajo reivindica normativamente el carácter democrático del gobierno representativo y señala que es necesario repensar la representación política para entender mejor distintas transformaciones políticas y los desafíos contemporáneos que enfrenta la democracia. Y la tercera sección, aborda al concepto de representación. En esta parte, se argumenta que las relaciones de representación política son necesarias para constituir una democracia capaz de articular una deliberación inclusiva con la adopción de decisiones colectivas que sean sometidas a procesos de rendición de cuentas. La apuesta es que esta noción puede aplicarse de manera transversal a los diversos procesos de decisión y actuación públicos que tienen lugar en los sistemas políticos.

\section{La representación política como problema}

Los estudios de opinión pública y participación política en las democracias contemporáneas, sean éstas consolidadas o emergentes, han motivado a los especialistas a analizar fenómenos como la desafección por parte de los ciudadanos hacia las instituciones y la participación política formal (Torcal y Montero, 2006) o lo que se ha denominado "déficit democrático" (Norris, 2011). Estos fenómenos parecen reflejar, de acuerdo con Warren, "un desacoplamiento entre las capacidades y las demandas de los ciudadanos" y las "capacidades de las instituciones políticas para agregar esas demandas ciudadanas e integrarlas en una gobernanza efectiva y legítima" (Warren, 2009:19). La explicación de estos fenómenos es multidimensional, pero no puede ser desligada del funcionamiento 
de las instituciones representativas de las democracias contemporáneas.

Del mismo modo y sin pretender exhaustividad, son diversas las conjeturas que se pueden hacer para entender la desafección o el desencanto que pueden generar los partidos y los gobiernos electos. Por ejemplo, si se trata de un régimen democrático recién instaurado tras una fase de autoritarismo, el público puede esperar una rápida y efectiva salida de una crisis económica, un acelerado crecimiento del producto interno bruto o bien, en algunos casos especiales, luego de atravesar por una dictadura en la que se cometieron violaciones a los derechos humanos, que se adopten medidas categóricas de impartición de justicia (Dutrénit y Varela, 2010). Los gobiernos electos pueden responder a las expectativas ciudadanas si consiguen aprovechar sus oportunidades o si cuentan con partidos responsables o liderazgos vigorosos. Pero también es probable que encuentren obstáculos difíciles de superar, tales como: una mayoría opositora en el Congreso, fuertes presiones de los grupos de interés, o simplemente carecer de la voluntad o la visión para cumplir con las expectativas del electorado.

Sin embargo, un desempeño errático por parte de un gobierno que llegó al poder para dar respuesta a grandes expectativas públicas, probablemente perjudicará la confianza en las instituciones representativas, y con ello la sensación de decepción o desencanto político puede magnificarse si se presentan escándalos de fraude o corrupción en las instituciones públicas que quedan impunes, ya sea porque el sistema no tiene la capacidad de sancionarlos, o por la complicidad entre grupos enquistados en las instituciones. Además, los medios de comunicación pueden desempeñar un rol central en promover el escrutinio y la crítica pública, pero también el inducir el descrédito hacia el sistema político, el orden constitucional o los partidos políticos.

Asimismo, el desencanto por el funcionamiento de la democracia representativa puede no estar basado simplemente en un asunto de percepción. El sistema representativo puede estar respondiendo de manera inadecuada o deficiente en sus acciones de gobierno. Las políticas públicas pueden no responder a las demandas de la mayoría de los ciudadanos, sino a los intereses de grupos con acceso privilegiado a las élites gobernantes. Los grupos de interés no solo están constituidos por empresas o corporaciones de negocios (Ross Schneider, 2011), sino también por sindicatos o agrupaciones o poderes fácticos de distinta índole (Olvera, 2012), que pueden incidir para detener, retrasar o sacar de la agenda temas de interés general. En este contexto, hay que contar también el poder de las grandes agrupaciones religiosas -la Iglesia Católica, por ejemplo-, o la influencia política que puede ejercer el Ejército. Por si fuera poco, en democracias débiles, los grupos de interés asociados a ciertas actividades del crimen organizado pueden corromper aceleradamente a las instituciones representativas. Así, el tema de la captura de la política pública por parte de intereses particulares remite a un problema de orden fundamental: las capacidades del Estado para actuar con eficiencia, oportunidad, eficacia y legalidad. No obstante, en América Latina, la consolidación del Estado continúa enfrentando desafíos y desafiantes (Eaton, 2012).

Desde luego, los problemas de desempeño de los gobiernos democráticos están determinados también por la forma en que funcionan los partidos políticos, el sistema de partidos y las instituciones legislativas. De este modo, el sistema de partidos puede estar integrado por organizaciones desestructuradas, inestables y poco institucionalizadas (Mainwaring y Zoco, 2007). Por lo tanto, los sistemas con estas características suelen convivir con acendradas prácticas de neopatrimonialismo, clientelismo y corporativismo. Cuando esto acontece, el modelo de representación basado en la conexión ideológica y programática entre individuos, representantes y partidos políticos encuentra dificultades para operar (Kitschelt y Wiklinson, 2007). En consecuencia, las políticas públicas se ven distorsionadas por el tipo de relación política que se establece: en lugar de que sea el electorado el que autoriza y controla a sus representantes, son los representantes e intermediarios políticos los que movilizan a grupos concretos de votantes a cambio de concesiones particularistas. La inestabilidad política y los sistemas de partidos poco institucionalizados favorecen también la fragmentación del espectro político y el surgimiento de liderazgos populistas y antisistema, con lo cual se presenta un fenómeno que 
Von Byme (2011) describe como "sobrerrepresentativo": el vínculo estrecho e inmediato entre un líder carismático y las masas populares, que basa buena parte de su atractivo en deslegitimar a las instituciones representativas.

Paralelamente, las legislaturas pueden estar poco institucionalizadas, contar con débiles elementos de apoyo técnico y encontrarse en manos de representantes poco profesionalizados (Saiegh, 2010). Asimismo, las relaciones entre los poderes ejecutivo y legislativo pueden alcanzar altos niveles de confrontación y entrampamiento, suscitando la demanda de mayores poderes para los presidentes, nuevas reglas electorales hechas a la medida de los partidos con representación legislativa, o el surgimiento de políticos antisistema.

En suma, el funcionamiento de las instituciones en los regímenes democráticos es un factor determinante de las dificultades que enfrentan los gobiernos electos para impulsar políticas públicas estables, flexibles y orientadas hacia el interés público (Scartascini et. al., 2010). Por eso, para proporcionar respuestas a los déficits de desempeño de la democracia se ha difundido la reivindicación de nuevas formas de acción ciudadana y de participación pública (Newton, 2012). Es muy probable que la ampliación de las alternativas de acción democrática pueda contribuir a mejorar la calidad de las políticas públicas, pero: ¿esto significa que es momento, no de complementar, sino de prescindir en lo posible de la política representativa?

\section{Revisitar las cuestiones representativas}

Es innegable que el funcionamiento de los regímenes democráticos puede no estar respondiendo al ritmo que una ciudadanía informada y exigente demanda. Este hecho, sin embargo, no debe dar paso a la convicción de que el problema radica en el carácter representativo de la democracia, o inclusive, en lo supuestamente inapropiado que resultarían las relaciones de representación para enfrentar los problemas colectivos. Tales planteamientos incurren en la falta de simplificar la problemática $\mathrm{y}$, como se dice habitualmente, "arrojan de la bañera al niño junto con el agua sucia”. Esta sección tiene el objetivo de mostrar que las instituciones y la política representativa no son, en principio, elementos antagónicos del fortalecimiento democrático.

Una primera cuestión que es necesario abordar, es la idea de que la democracia representativa es una forma de gobierno insuficientemente democrática, puesto que implica una separación entre la opinión y la participación de la ciudadanía y el ejercicio de la autoridad. Desde ese punto de vista podría decirse que el elemento representativo constituye en sí mismo un elemento que fractura o imposibilita la plena legitimidad democrática. En palabras de Barber (1984:145): "La representación es incompatible con la libertad porque delega y aliena la voluntad política a costa de un genuino autogobierno y autonomía (Barber, 1984:145, traducción propia)". Acá no se trata sencillamente de una cuestión de opinión pública, pues el problema no se limita a ser un asunto de qué tanto la ciudadanía está satisfecha con el funcionamiento del régimen o si tiene confianza en el parlamento o se identifica con los partidos políticos. Se trata de un problema que persiste inclusive en el hipotético caso del óptimo funcionamiento de las instituciones representativas.

Por un lado, el gobierno representativo, por definición, implica que las decisiones, leyes y políticas que regirán a una colectividad son adoptadas por agentes que actúan en nombre de los representados. Esto, a su vez, significa que la relación política que se establece entre quienes detentan la autoridad en última instancia y las decisiones o acciones del gobierno es indirecta. Esta relación indirecta resulta incómoda para una concepción de la democracia en la que se espera un vínculo de inmediatez entre el ciudadano y las decisiones colectivas. Desde tal perspectiva, idealmente tendrían que ser los ciudadanos en su conjunto los que intervengan y decidan de forma directa sobre las cuestiones públicas. La democracia representativa, en pocas palabras, sería un sucedáneo imperfecto de una auténtica democracia.

Por otro lado, la desconfianza democrática hacia el modelo representativo de gobierno no es infundada. El gobierno representativo es heredero de una tradición elitista y aristocrática (Manin, 1997; Ferejohn \& Rosenbluth, 2009). Además, 
los sistemas representativos surgieron primero como una forma de gobierno que estaba destinado a proteger las libertades y los privilegios de unos pocos. Así, el gobierno representativo estaba pensado como un antídoto en contra de las comunidades democráticas de la Grecia clásica o el renacimiento italiano, que tenían una vida corta y problemática. Esto queda expresado en las palabras de James Madison, uno de los autores de la Constitución norteamericana: "Por eso estas democracias han dado siempre el espectáculo de su turbulencia y sus pugnas; por eso han sido siempre incompatibles con la seguridad personal y los derechos de propiedad; y por eso, sobre todo, han sido tan breves sus vidas como violentas sus muertes" (Hamilton, Madison y Jay, 2001: 39). Cabe destacar que el gobierno representativo se definió en sus inicios por oposición a los sistemas democráticos de la antigüedad, pero esos mismos sistemas de gobierno se convirtieron en regímenes democráticos tiempo después, como resultado de diversos procesos de lucha y negociación en los cuales se hicieron extensivos los derechos políticos a la población adulta de esas sociedades. Aún así, en el marco de los sistemas políticos democráticos, con elecciones abiertas y competitivas, la operación de las instituciones representativas siguió asociada a una concepción elitista de la representación. Esta visión queda plasmada en trabajos como los de Schumpeter (1970), quien favorecía un sistema periódico de rotación de las elites y los liderazgos en el gobierno.

Por su parte, la concepción elitista de la democracia ha ocupado un lugar prominente en el desarrollo posterior de la teoría democrática, pero desde su formulación se ha generado un prolífico debate que ha dado lugar a una comprensión mucho más inclusiva y sofisticada del gobierno democrático. La cuestión es sencilla: la democracia no puede ser concebida solamente como un sistema de rotación de las élites. Con esto, la concepción schumpetereana es un afluente del desarrollo posterior de la concepción procedimental de la democracia, que se ha convertido, a su vez, en el punto de partida de los debates contemporáneos (Dahl, 1971; Munck, 2007). Una reinterpretación deliberativa de la concepción procedimental coloca el énfasis en las instituciones, normas y condiciones que permiten convertir en autoridad jurídica y administrativa los procesos colectivos de formación de la opinión pública (Habermas, 1998). Esta concepción, a su vez, ha sido recuperada por otros modelos de democracia que reivindican formas más participativas y colaborativas de hacer política. Por un lado, se encuentra una tradición propiamente participativa, que aboga por modalidades de involucramiento directo y activo de los individuos en los asuntos colectivos (Fung y Wright, 2003). Por otro lado, se encuentra el modelo de la democracia deliberativa que destaca la importancia del diálogo público como una forma de alcanzar acuerdos y dar legitimidad a las decisiones políticas (Guttman y Thompson, 2004).

Una de las vertientes de la teoría de la democracia, precisamente, ofrece elementos para cuestionar la idea de que la representación es necesariamente menos democrática que la participación directa en los asuntos públicos (Plotke 1997; Mansbridge, 2003). En primera instancia, no está de más hacer notar que la escala y complejidad de los sistemas políticos contemporáneos hacen inviable algún modelo de democracia directa. En relación con esto, es poco realista esperar que millones de personas se involucren directamente en las decisiones políticas y legislativas de un régimen, aunque se tenga la expectativa de que el desarrollo tecnológico ponga remedio a este problema algún día. Sin embargo, aunque las tecnologías de la información llegan a comunicar instantáneamente a millones de personas subiste un problema de carácter funcional. Las decisiones políticas involucran conocimiento especializado y dominio de la técnica jurídica; demandan a la vez profesionalización, capacidades de negociación, deliberación e intercambio, y recursos que no están distribuidos de manera uniforme: tiempo, dinero y disposición.

Por consiguiente y abordando los aspectos medulares de la cuestión, se podría decir que el proceso democrático está constituido por un ciclo temporal que contiene diversos momentos de deliberación, decisión, actuación y evaluación públicos. De acuerdo con Urbinati (2006), una concepción representativa de la política democrática puede dar cuenta mejor de ese proceso que una concepción directa, puesto que esta última implica que el acto democráticamente 
relevante es el de la intervención de los ciudadanos en el momento de la decisión política. Este señalamiento no va dirigido en contra de los mecanismos de democracia directa que constituyen complejos instrumentos de gobernanza que se han difundido a lo largo de los sistemas políticos en el mundo (Altman, 2011). Lo que se pone en cuestión son las visiones de la democracia que pasan por alto los procesos de constante retroalimentación entre opiniones, decisiones, acciones y juicios públicos que constituyen el ejercicio de la soberanía popular.

La reivindicación del pleno carácter democrático de los regímenes representativos puede hacerse, entonces, a partir de tres consideraciones adicionales. En primera instancia, se debe señalar que las democracias representativas son sistemas que se basan en la institucionalización de derechos ciudadanos que facultan el ejercicio de diversas formas de expresión, influencia y agencia política (O’Donnell, 2010). Éstas a su vez, están construidas sobre instituciones estatales que, al menos como expectativa última, deben proteger y promover la dignidad de las personas, su integridad individual y su patrimonio; establecer condiciones para el ejercicio de las libertades de credo, expresión y asociación; y crear condiciones para el ejercicio de la participación en los procesos políticos bajo la forma de electores, candidatos, representantes y/o gobernantes. Sobre este entramado de normas, instituciones, condiciones y procesos políticos operan los gobiernos, en contextos en los que la ciudadanía tiene la posibilidad de involucrarse en múltiples formas de actuación y participación política.

La segunda consideración que se toma en cuenta es que existen fallas y deficiencias en el funcionamiento de las democracias representativas. Pero esto no significa que las instituciones representativas deban ser descartadas, significa que las instituciones representativas pueden ser mejoradas en muchos sentidos, como en el de tener un vínculo más estrecho y cercano con la ciudadanía, de promover procesos más eficientes y expeditos de decisión pública, de incorporar voces e intereses que han permanecido invisibles o silenciados hasta el momento, o de alcanzar un funcionamiento más imparcial y menos proclive a beneficiar sistemáticamente a ciertos grupos o intereses, entre otras opciones de reforma y mejora.

La tercera consideración se remite a un debate en el plano de la teoría normativa. Más allá de la necesidad de enfrentar los desafíos concretos de reforma que enfrentan las instituciones representativas, es necesario tener una comprensión más sofisticada del gobierno representativo y la representación democrática. En este plano sobresalen trabajos como los de Manin (1997) y Urbinati (2006), pues han propuesto una manera de entender la democracia representativa en la que adquieren centralidad los procesos de comunicación y debate público. Para Manin (1997), la democracia representativa es un sistema que promueve una suerte de elitismo meritocrático, fundamentado en el intercambio permanente de los representantes con la opinión pública, la necesidad de justificar las decisiones adoptadas y de someterse al veredicto popular en las urnas. Un giro todavía más claro en esa dirección ha sido desarrollado por Urbinati (2006), quien considera que la democracia no es una sucesión de eventos discretos en los que la comunidad se reúne para adoptar decisiones políticas (Urbinati, 2006), sino un proceso ineludiblemente constituido a lo largo del tiempo, en el que las decisiones colectivas responden, en última instancia y a través de mecanismos diversos de intervención política, a los ajustes y cambios en las preferencias de una ciudadanía heterogénea en sus intereses y experiencias políticas. En sus propios términos, "(en la democracia representativa), la política es una narración ininterrumpida de propuestas y proyectos que unifica a los ciudadanos y requiere de ellos que se comuniquen en torno a un espacio normativo y a lo largo del tiempo (traducción propia)" (Urbinati, 2006:226) Del mismo modo, la tesis de Urbinati (2006:) invita a repensar seriamente el rol de la representación de la política democrática: "Enfocarse en la presencia a través de las ideas y el discurso, revela que la participación y la representación no son formas alternativas de democracia, sino que son formas relacionadas en la constitución de un continuo entre el juicio político y la acción en las democracias modernas (traducción propia, énfasis en el original)" (Urbinati, 2006:3). 
Así, la necesidad de repensar la representación se hace manifiesta también al considerar la emergencia de múltiples instancias de decisión y actuación en la gobernanza contemporánea. John Keane (2011), señala que la concepción que se tiene actual de la democracia representativa está vinculada a una idea en la que la política gira en torno a las instituciones representativas del Estado nacional. Esta idea es imprecisa -afirma-, pues a partir de la Segunda Guerra Mundial se ha desarrollado un sistema de organización política multipolar y con forma reticular. Es decir, se trata de un sistema al que denomina "democracia de monitoreo", en el que las instituciones representativas convencionales constituyen una modalidad de control y acción públicos, como lo son también diversas agencias nacionales e internacionales de supervisión, consulta, planeación o ejecución de programas. Igualmente, señala que en este régimen las instituciones representativas nacionales han perdido el lugar primordial que se les ha atribuido, pero eso no significa que se vuelvan intrascendentes o que cedan su lugar a modelos de gobernanza participativos en un sentido literal (Keane, 2011). Para este autor, la proliferación de nuevas instancias de poder público le da una nueva centralidad a las dinámicas representativas. Así pues, en un escenario multipolar, la representación política es el vehículo que conecta a los diferentes públicos con las funciones que cumplen las agencias estatales y sociales que intervienen en las actividades de gobernanza y "monitoreo".

\section{La configuración de la política representativa}

La representación política es un concepto que resulta útil para analizar la manera en que se articulan diversas formas de comunicación, participación, decisión y actuación política. Su aportación a la política democrática se basa, en el plano más general, en promover la inclusión política y la conducción de los asuntos públicos en pro del interés de quienes son representados. Este postulado es aplicable al funcionamiento de las instituciones representativas, pero también es válida para las diversas manifestaciones de acción e intervención públicas que se observan en los sistemas políticos.
En relación con esto, la tarea fundamental de la representación política es inducir una actuación por parte de los representantes, de tal forma que se promueva el interés de los representados en un marco de rendición de cuentas. Este planteamiento, formulado originalmente por Hanna Pitkin, continúa con vigencia, aunque requiere ser adaptado en diversos sentidos. Pitkin (1967), a su vez examinó los múltiples usos que a lo largo de la historia de la teoría política se le ha dado a la representación política. Al encontrarse con la disyuntiva acerca de si actuar "en lugar de" los representados significa obedecer un mandato expreso o si el representante debe actuar con plena independencia, Pitkin asume una posición clara: "representar" no significa "hacerse cargo" de alguien, en un sentido paternalista; ni tampoco "representa" quien solo consulta y sigue indicaciones. La representación política tiene lugar cuando "se actúa conforme el interés de los representados, de una manera responsiva hacia ellos" (Pitkin, 1967: 209). Esta es la base de su concepción del gobierno representativo, en el que: “...el pueblo realmente actúa a través de su gobierno, y no es un mero receptor pasivo de sus actos", pues los "gobernados deben ser capaces de acción y juico, capaces de iniciar actividades de gobierno, de tal manera que el gobierno puede ser concebido como respondiéndoles a ellos" (Pitkin, 1967: 232).

Pitkin (1967) arriba a una vigorosa concepción de la democracia representativa, afirma que: el gobierno democrático es representativo cuando de manera fehaciente los gobernantes electos promueven los intereses de sus representados y responden a sus demandas. En este planteamiento, sin embargo, se pasa por alto la diferencia entre la teoría de la representación política y la teoría sobre las instituciones y el funcionamiento de la democracia representativa. En otras palabras, la teoría de la representación política se desarrolla, primero, bajo los parámetros normativos de la democracia; y segundo, se inscribe en el marco de la democracia representativa. Esta serie de desplazamientos en el sentido del concepto de representación está en la raíz de las dificultades encontradas para repensar la relación entre la representación y la democracia en términos más amplios. 
No obstante, para formular una comprensión más versátil de la representación política es necesario mostrar tres señalamientos. El primero es que el concepto de representación no está ligado, por definición, a la democracia ni a sus instituciones de gobierno. Lo que define a la representación es el cumplimiento de las reglas y condiciones para que un representante sea reconocido como tal (Rehfeld, 2006). Además no tiene que representar a algún distrito electoral ni haber sido electo popularmente; puede representar a un país o nación, y haber sido designado por un dictador. La representación política, entonces, es una relación que puede cumplir con funciones muy distintas, dependiendo de los ámbitos de la vida social en los que se manifieste. Así, las relaciones representativas se presentan en los ámbitos laborales, universitarios, profesionales, gubernamentales, asociativos, entre otros.

El segundo señalamiento se basa en otra de las aportaciones de Rehfeld (2006): la articulación de la representación con la democracia tiene lugar cuando el ejercicio de la representación se realiza en el marco de relaciones o instituciones que se conducen con apego a las normas democráticas. Esto orienta, desde luego, a preguntarse cómo se definen las normas democráticas con las que se habrá de evaluar la calidad de la representación política. Ahora bien, una respuesta a esta interrogante es que son democráticas todas aquellas instituciones, condiciones y prácticas que se realizan en el marco de los regímenes democráticos contemporáneos, y esta respuesta tiene algo de tautológica, pues remite al régimen democrático como explicación final de lo que hace democrática a una institución política o a un determinado proceso. No obstante, para escapar de esta tautología, se debe mencionar que los regímenes democráticos son sistemas de gobierno que encarnan y materializan los principios democráticos de igualdad pública e inclusión política (Christiano, 2008; Warren, 2006). Es decir, no hay nada intrínsecamente democrático en las elecciones o la formulación de leyes. Lo que hace democráticas a las elecciones o la función legislativa es el marco institucional y las condiciones en las que se llevan a cabo. Las elecciones democráticas, por ejemplo, requieren la universalidad del derecho al sufragio; una contienda entre distintas alternativas políticas; una competencia electoral abierta, basada en arreglos que fomenten la equidad en la competencia y la libertad de expresión; e imparcialidad en el conteo de los votos y la adjudicación de diferencias en la conducción del proceso, entre otros factores. De la misma manera, la producción legislativa podrá reclamar legitimidad democrática cuando esté a cargo de representantes que han sido electos popularmente y se hayan seguido los procedimientos establecidos en la normatividad parlamentaria. En cambio, no son consideradas democráticas las leyes que son adoptadas por parlamentos constituidos por legisladores que han sido designados por un autócrata o un partido hegemónico, o que ganaron su escaño en elecciones que no pueden ser consideradas ni libres ni competitivas. Tampoco son democráticas las políticas surgidas de la voluntad de un autócrata, por más que esas leyes o políticas pretendan promover el bienestar del pueblo o por más que el dictador cuente con respaldo popular.

Remitirse a las normas democráticas en su sentido más abstracto permite ampliar su alcance: se puede atribuir rasgos democráticos a toda forma de participación, decisión y acción política que, en alguna medida, incorpore elementos coherentes de inclusión efectiva e igualdad pública de los implicados por una decisión política. Es en este sentido, se puede hablar de la "democratización" de la gobernanza y las políticas públicas (Warren, 2009b): acontece cuando se incorporan mecanismos de decisión y actuación públicos que requieren, en alguna medida, ampliar los procesos de inclusión y consulta de los implicados por una política en la toma de decisiones.

Con el tercer señalamiento, se encuentra la relevancia de los procesos de comunicación y deliberación en la configuración de las relaciones representativas. Este componente es el que ha sido resaltado por Urbianti (2006) en su concepción de la democracia representativa como un sistema en el que la voluntad y el juicio político de la ciudadanía se representan a través de la circulación de ideas y discursos en la esfera pública y en las instituciones parlamentarias. Otra aportación en este campo ha sido realizada por Saward (2010) con el concepto de reivindicaciones representativas (representative claims). Para Saward (2010), las demandas, planteamientos o 
reivindicaciones representativos son elementos que le dan sentido a las relaciones de representación. Por consiguiente, la representación en tanto actividad política implica recurrir a herramientas discursivas, retóricas, e inclusive de actuación o representación teatral.

Algunos ejemplos conspicuos provienen de la ola de movimientos y protestas sociales que se han registrado en algunos países latinoamericanos, en Europa y los Estados Unidos. Estas manifestaciones inician con expresiones puntuales de protesta que espontáneamente se convierten en protestas masivas, reproducidas en numerosas ciudades. En España el movimiento de los Indignados surgió en mayo de 2011, cuando un grupo de personas de la plataforma "Democracia Real Ya", decidió acampar en la Puerta del Sol para manifestarse pacíficamente en contra del poder de la banca y la corrupción en el poder político. En ese mismo año, en los Estados Unidos, se originó el movimiento "Ocupa Wall Street" que, con proclamas como "Nosotros somos el 99\%", denunció la connivencia entre financieros, banqueros y políticos, responsabilizándolos de la corrupción y la desigualdad que perjudican a la mayoría de la población. Del mismo modo, y a raíz de una ligera alza en el costo del transporte público, coincidiendo con el certamen internacional de fútbol, en Brasil se presentó un fenómeno semejante, que se desató una serie de multitudinarias protestas en varios cientos de ciudades de ese país, para denunciar su inconformidad con el gasto gubernamental en torneos deportivos internacionales, sin mejorar antes la calidad de una amplia gama de servicios sociales. Con todo esto y dejando de lado, por un momento, el impacto legislativo o en políticas públicas concretos que pudieran tener, estos movimientos ilustran el rol que juegan los símbolos y los emblemas en la construcción de reivindicaciones representativas. A grandes rasgos, las protestas de los indignados reivindican el interés y el bienestar de las mayorías, ante lo que denuncian como diversas formas de corrupción del poder público a manos de políticos y grupos de interés.

Con base en los antecedentes mencionados, puede afirmarse que la representación política es una forma de relación política constituida por procesos de autorización y rendición de cuentas que, en términos democráticos, tiene como finalidad promover los intereses comunes o públicos de una colectividad. Por tanto, este postulado amerita algunas precisiones adicionales: la primera es que, como indican Warren y Urbinati (2008), autorizar significa que una colectividad elige o selecciona a uno o varios representantes para actuar en relación con un tema u objeto de interés para esa colectividad; "rendir cuentas", a su vez, supone que la colectividad cuenta con algún tipo de mecanismo que induce a los representantes a ofrecer explicaciones de sus actos, o bien, a ser objeto de alguna sanción. Aunque insuficientes para inducir un comportamiento representativo (Manin et. al., 1999), las elecciones constituyen uno de los mecanismos institucionales más sofisticados para constituir la representación política, pues a través de las elecciones los ciudadanos eligen representantes, y es también mediante elecciones que los votantes llaman a cuentas al gobierno.

Sin embargo, hay que añadir que es posible identificar otros mecanismos de autorización. Como primera consideración, Urbinati y Warren (2008), describen numerosas formas de representación democrática no-electoral, que asumen la forma de agentes auto-autorizados o múltiples espacios de "representación ciudadana". Estas manifestaciones representativas quedan expresadas en las reivindicaciones de organizaciones internacionales, grupos de interés, asociaciones filantrópicas, actividades periodísticas, consejos consultivos, audiencias públicas, foros deliberativos, paneles de especialistas, protestas colectivas y otros.

Una segunda consideración está relacionada con lo que implica "actuar en interés de los representados de una manera responsiva hacia ellos". El punto a destacar es que, las elecciones no son el único mecanismo que puede inducir un comportamiento públicamente orientado; también es posible promover dinámicas de inclusión política y de rendición de cuentas capaces de fortalecer el control popular en los asuntos públicos mediante distintos instrumentos formales e informales que permiten representarlos y promover los intereses colectivos de determinados sectores sociales. De acuerdo con esto, la articulación de ese potencial de inclusión y rendición de cuentas que tienen los modelos participativos 
de gobernanza con la representación de nuevas voces y sectores sociales es precisamente uno de los temas emergentes en el estudio de la construcción participativa de la democracia (Gurza e Isunza, 2010).

En tercer lugar, hay que considerar que cada uno de los términos que constituye una relación de representación está inmerso en procesos de constante reconfiguración política y simbólica, en los que desempeñan un rol clave los discursos y las reivindicaciones políticas. Sirva para propósitos ilustrativos hacer una referencia sucinta a la reivindicación de los derechos de las víctimas en la "guerra" contra el narcotráfico emprendida por la administración de Felipe Calderón (2006-2012) en México. El Presidente Calderón en México impulsó un programa de combate contra los cárteles de droga en el país, que contempló una serie de reformas legales y administrativas, acciones preventivas puntuales y una política de combate directo al crimen organizado mediante el ejército y las fuerzas armadas del Estado. Los alcances de tales acciones requieren ser evaluados de manera sistemática e integral, pero más allá de lo reportado en sus informes de gobierno, la administración calderonista, por ejemplo, dejó pendiente ofrecer cifras oficiales y fidedignas de los decesos asociados al combate del crimen organizado, de personas desaparecidas y de desplazados debidos a la violencia. No obstante, ha sido a partir de la iniciativa de especialistas y organizaciones sociales, que se ha recopilado y sistematizado información sobre la seguridad pública (Aguayo y Benítez, 2012). De la misma forma, fueron organizaciones sociales, familiares de víctimas, personalidades públicas y el Movimiento por la Paz con Justicia y Dignidad (MPJD), quienes consiguieron abrir espacio a la reivindicación de los derechos de las víctimas y sus familiares (véase: Azaola, 2012; http//:movimientoporlapaz. $\mathrm{mx})$. Con esto, fue tal el eco en la opinión pública nacional e internacional que tuvo este movimiento que el Presidente Calderón accedió a sostener dos encuentros con los representantes de tal movimiento, mismos que se realizaron en junio y octubre de 2011, respectivamente. El MPJD y otras organizaciones consiguieron impulsar la Ley General de Víctimas y, aunque fue vetada por Calderón, finalmente fue promulgada por la administración siguiente el 9 de enero de 2013.

Aunque descrito con trazos muy gruesos, este caso ilustra la manera en que diversas organizaciones sociales, articuladas en torno a un movimiento, consiguen reivindicar a las víctimas de la violencia asociada al crimen organizado y al combate emprendido por el gobierno en contra de los cárteles de la (omitir "la") droga. Al hacer estas reivindicaciones, fungen como representantes de una demanda pública para que el Estado mexicano se asuma como garante de los derechos, la dignidad y la justicia. Así, al articularse con actores políticos en la Cámara de Diputados y el Senado, el movimiento consiguió que se aprobara una ley para la protección de los derechos de las víctimas. Este caso ilustra la importancia de profundizar en el análisis de este tipo de procesos, prestando atención no solamente a la interacción entre movimientos y organizaciones sociales, actores políticos, agendas públicas, y procesos legislativos, sino también a la manera en que las demandas y reivindicaciones construyen relaciones representativas dinámicas y cargadas de narrativas y elementos simbólicos.

Una de las rutas que se abre para la agenda de investigación sobre la representación política consiste en poder dar cuenta de cómo se construyen relaciones de representación y rendición de cuentas que favorecen al interés público. Esto puede llevarse a cabo analizando las dinámicas de los partidos, las elecciones y los órganos legislativos, o estudiando las formas emergentes de representación no-electoral. Parte del desafío, sin embargo, consiste en adoptar una perspectiva que permita analizar la configuración de la política representativa de manera transversal, estudiando la manera en que se articulan las redes asociativas, foros y espacios públicos y las dinámicas legislativas.

\section{Reflexiones finales}

Este trabajo ha planteado que la representación política cumple con un rol constitutivo en el gobierno democrático. A primera vista puede parecer una afirmación trivial y evidente, pues no parece que los regímenes democráticos vayan a prescindir de las legislaturas, las elecciones 
o los partidos políticos -ni tendrían por qué hacerlo-. El propósito no ha sido señalar lo obvio, sino aportar elementos para la construcción de un espacio conceptual que permita dialogar más activamente a los estudios sobre la participación, los espacios públicos, la teoría de la democracia y las instituciones de los regímenes democráticos.

Uno de esos elementos es la idea de que la representación democrática se compone de procesos electorales y las políticas legislativas, pero también de debates, discursos y reivindicaciones sobre lo que se representa, cómo y de qué manera. Si la representación democrática implica actuar de manera congruente con las demandas de intereses de aquellos a quienes se representa, es necesario señalar que el ejercicio de la representación requiere explicar los procesos mediante los que se configuran los elementos del ejercicio representativo. Este paso puede darse en la medida en que los aspectos formales e institucionales del ejercicio de la representación sean considerados solo una parte de aquello que debe estudiarse, pues sus otros componentes son entidades cambiantes y controvertidas: el interés público, las alternativas de acción, los representantes, los sujetos representados, los resultados de la acción pública, entre otros. Acá, el punto de relevancia para la teoría de la democracia es que en esos procesos de configuración política y discursiva del ejercicio de la representación se ponen en juego dinámicas de inclusión y actuación políticas, que en un sentido o en otro, pueden ampliar o restringir el control democrático de los ciudadanos sobre la acción pública.

Este planteamiento pretende enfatizar aquellos aspectos del ejercicio de la representación democrática a los que con frecuencia se hace alusión en el estudio de las dinámicas partidistas, electorales y legislativas, pero que pocas veces son analizadas de manera sistemática. Este planteamiento, a su vez, ha sido formulado de forma tal que pueda aplicarse también al estudio de las dinámicas asociativas, los movimientos sociales y la construcción de mecanismos participativos de gobernanza. Las reivindicaciones de inclusión, rendición de cuentas y actuación a favor del interés público también se realizan en el marco de los debates en diversos espacios públicos. En gran medida, las innovaciones institucionales de carácter participativo ponen en juego diversas formas de representación pública. Sin embargo, para analizar mejor su funcionamiento, sus desafíos y sus contribuciones es necesario incorporar al análisis la manera en que se construyen las dinámicas representativas.

Finalmente, el estudio de la política representativa, entonces, puede considerarse como algo transversal a las dinámicas asociativas, la conducción de las políticas públicas, los debates en la esfera pública y el funcionamiento de las instituciones electorales y legislativas. Es necesario avanzar en el estudio transversal de la política representativa, pues esto puede contribuir a examinar la manera en que se articulan diversos procesos de participación, deliberación, decisión, actuación y evaluación públicos en las democracias actuales.

\section{Referencias bibliográficas}

Aguayo, S. y Benítez Z. R. (eds.). (2012). Atlas de la seguridad y la defensa de México 2012. México: Colectivo de Análisis de la Seguridad con Democracia, Open Society.

Alonso, S., Keane, J. y Merkel, W. (eds.) (2011). The Future of Representative Democracy, Cambridge: Cambridge University Press.

Altman, D. (2011). Direct Democracy Worldwide New York: Cambridge University Press.

Avritzer, L. (2002). Democracy and the Public Space in Latin America. Princeton: Princeton University Press.

Azaola, E. (2012). "El Movimiento por la Paz con Justicia y Dignidad". Desacatos, 40: 159-170

Barber, B. (1984). Strong Democracy: Participatory Politics for a New Age. Berkeley: University of California Press.

Christiano, T. (2008). The Constitution of Equalitiy: The Authority of Democracy and Its Limits. Oxford: Oxford University Press.

Dagnino, E., Olvera, A., y Panfichi, A. (2006). La disputa por la construcción democrática en América Latina. México: Fondo de Cultura Económica.

Dahl, R. (1971), Poliarchy: Participation and Opposition. New Heaven: Yale University Press. 
Dutrénit, S. y Varela, G. (2010). Tramitando el pasado: violaciones de los derechos humanos y agendas gubernamentales en casos latinoamericanos. México: FLACSO.

Eaton, K. (2012). "The State of the State in Latin America: Challenges, Challengers, Responses and Deficits. Revista de Ciencia Política, núm. 33, vol. 3, pp. 643-657.

Ferejohn, J. y Rosenbluth, F. (2009). "Electoral Representation and the Aristocratic Thesis". En Shapiro, I., et. al., (eds.), Political Representation. Cambridge: Cambridge University Press, pp. 271-304.

Fung, A. y Wright, E. O. (eds). (2003). Deepening Democracy: Institutional Innovation in Empowered Participatory Governance. Londres: Verso.

Gurza, A. y Isunza, E. (2010), "Precisiones conceptuales para el debate contemporáneo sobre la innovación democrática". En Isunza, E., y Gurza, A. (coords.), La innovación democrática en América Latina. Tramas y nudos de la representación, la participación y el control social. México: CIESASUniversidad Veracruzana, pp. 19-82.

Guttman, A. y Thompson, D. (2004). Why Deliberative Democracy? Princeton: Princeton University Press.

Habermas, J. (1998), Facticidad y validez. Madrid: Trotta.

Hamilton, A., Madison, J., y Jay, J. (2001[1780]), El Federalista, México, Fondo de Cultura Económica, ( $2^{\text {a }}$ edición)

Keane, J. (2011). "Monitory Democracy?". En Alonso,S., et. al. The Future of Representative Democracy. Cambridge: Cambridge University Press, pp. 212-235.

Kitschelt, H. y Wilkinson, S. (2007). "CitizenPolitician Linkages: An Introduction". En Kitschelt, H., y Wilkinson, S. (eds.), Patrons, Clientes, and Policies:Patterns of Democratic Accountability and Political Competition. Cambridge: Cambridge University Press, 2007, pp. 1-49.

Mainwaring, S., y Zoco, E. (2007). "Secuencias políticas y estabilización de la competencia partidista: volatilidad electoral en viejas y nuevas democracias". América latina Hoy, núm. 46, pp. 147-171.
Manin B. (1997). The Principles of Representative Government. Cambridge: Cambridge University Press.

Manin, B. Przeworski, A. y Stokes, S. (1999). "Elections and Representation". En Przeworski, A., Stokes, S. y Manin, S. (eds.), Democracy, Accountability and Representation. Cambridge: Cambridge University Press, pp. 29-55.

Mansbridge, J. (2003). "Rethinking Representation". American Political Science Review, vol. 97, núm. 4, pp. 515-528.

Munck, G. (2007). "The Study of Politics and Democracy: Touchstones of a Research Agenda”. En Munck, G. (ed.), Regimes and Democracy in Latin America: Theories and Methods. Oxford: Oxford University Press, pp. 25-38.

Newton, K. (2012). "Curing the Democratic Malaise with Democratic Innovations". En Newton, K., y Geisse, B. (eds.), Evaluating Democratic Innovations: Curing the Democratic Malaise? Nueva York y Londres: Routlegde, pp. 3-20.

Norris, P. (2011). Democratic deficit. Cambridge University Press.

O'Donnell, G. (2010). Democracy, Agency, and the State: Theory with Comparative Intent. Oxford: Oxford University Press.

Olvera, A. (2012). "Poderes fácticos y sistema político en México". En Espinoza V., y Monsiváis, A., El deterioro de la democracia: consideraciones sobre el régimen político, lo público y la ciudadanía en México. México: El Colegio de la Frontera Norte, pp. 121-148.

Parkinson, J. (2003). "Legitimacy Problems in Deliberative Democracy". Political Studies, 51(1), 180-196.

Peruzzotti, E. y Seele, A. (eds.) (2009). Participatory Innovation and Representative Democracy in Latin America. Washington, D.C., y Baltimore: Woodrow Wilson Center Press, The Johns Hopkins University Press.

Pitkin, H. F. (1967). The Concept of Representation. Berkeley: University of California Press. 
Plotke, D. (1997). "Representation is democracy". Constellations, 4, pp.19-34

Przeworski, A., Stokes, S. y Manin, S. (eds.) (1999). Democracy, Accountability and Representation. Cambridge: Cambridge University Press.

Rehfeld, A. (2006). "Towards a General Theory of Political Representation". The Journal of Politics, Vol. 68, núm. 1, pp. 1-21.

Rehfeld, A. (2010). "Offensive Political Theory". Perspectives on Politics, vol. 8, núm. 2.

Saiegh, S. M. (2010). "Active players or rubber stamps? An Evaluation of the Policymaking Role of Latin American Legislatures". En Scartascini, C., et al. (eds.) How Democracy Works: Political Institutions, Actors, and Arenas in Latin American Policymaking. Washington, DC: InterAmerican Development Bank and David Rockefeller Center for Latin American Studies, Harvard University, pp. 47-76.

Saward, M. (2010). The Representative Claim. Oxford: Oxford University Press.

Scartascini, C., Spiller, P., Stein, E., y Tomassi, M. (2010). “CCómo se juega en América Latina? Instituciones políticas, procesos de negociación y políticas públicas". En Scartascini, C., Spiller, P., Stein E., y Tomassi, M. (eds.), El juego político en América Latina: ¿cómo se deciden las políticas públicas? Colombia, Banco Interamericano de Desarrollo, pp. 1-32.

Schneider, B. R. (2010). "Business Politics and Policy Making in Contemporary Latin America”. En Scartascini, C. et. al. (eds.) How Democracy Works: Political Institutions, Actors and Arenas in Latin American Policymaking. Washington, DC: InterAmerican Development Bank and David Rockefeller Center for Latin American Studies, Harvard University, pp. 217-246.
Schumpeter, J. (1970). Capitalism, Socialism and Democracy. Nueva York: Harper Perennial [3a. Edición].

Sexto Informe de Gobierno de Felipe Calderón: Estado de derecho y seguridad. http://cort. as/3uMD. Acceso del 13 de abril de 2013.

Shapiro, I., Stokes, S., Wood, E.J., y. Kirshner, A. (eds.) (2009). Political Representation. Cambridge: Cambridge University Press.

Torcal, M. y Montero, J. R., (eds.) (2006). Political Disaffection in Contemporary Democracies: Social Capital, Institutions and Politics. Londres: Routledge.

Urbinati, N. (2006). Representative Democracy: Principles and Genealogy. Chicago: University of Chicago Press.

Urbinati, N. y Warren, M. (2008). "The Concept of Representation in Contemporary Democratic Theory". Annual Review of Political Science, vol. 11, pp. 387-412.

Von Byme, K. (2011). "Representative Democracy and the Populist Temptation". En Alonso,S., et. al. The Future of Representative Democracy. Cambridge: Cambridge University Press, pp pp. 50-73.

Warren, M. (2006). "Democracy and the State". En Dryzek, J., Honig, B. y Phillips, A. (eds.), The Oxford Handbook of Political Theory. Oxford: Oxford University Press, pp. 382-399.

Warren, M. (2009). "Citizen Participation and Democratic Deficits: Considerations from the Perspective of Democratic Theory". En DeBardeleben, J. and Pammett, J. (eds.), Activating the Citizen. Londres: Palgrave MacMillan, pp. 17-40.

Warren, M. (2009b). "Governance-Driven Democratization”. Critical Policy Studies, vol. 3, núm. 1, pp. 1-13. 
